\title{
PERANAN PENDIDIKAN AGAMA KRISTEN DI SEKOLAH TERHADAP PEMBENTUKAN IMAN ANAK
}

Friskilia Hesti

Paper Pengantar Filsafat

friskiliahesti@gmail.com

\begin{abstract}
ABSTRAK
Pendidikan agama di lingkungan sekolah memiliki peran yang besar dalam pembentukan karakter bagi anak-anak, dimana di lingkungan sekolah merupakan salah satu pendidikan yang dapat mempengaruhi perkembangan anak selanjutnya. Agar anak-anak memiliki kepribadian yang baik dan terhindar dari pelanggaran-pelanggaran moral, maka perlu adanya pembinaan agama sejak dini kepada anak-anak. Di sekolah anak-anak juga ditanamkan sifat-sifat yang baik, seperti nilai-nilai kejujuran, keadilan, hidup sederhana, sabar dan lain-lain. Sangatlah diperlukan peran dari berbagai pihak termasuk dan teristimewa guru Pendidikan Agama Kristen dalam mengontrol siswa yang terbawa arus oleh perkembangan tersebut. Tentu hal ini, diperlukan peran guru yang sangat serius untuk membentuk karakter siswa yang baik dan terpuji.
\end{abstract}

\section{PENDAHULUAN}

Dalam pendidikan karakter/ iman anak bukan merupakan satu-satunya cara untuk diperoleh melalui pendekatan pendidikan formal. Iman lebih dominan diperoleh dan dipelajari justru melalui budaya dan secara konkrit lebih banyak melalui keteladanan dan interelasi seharihari. Pendidikan sekolah formal bukan jaminan bagi pendidikan iman. Tentu ada saja hal baik yang diperoleh melalui pendidikan sekolah formal, khususnya hal kognitif. 1

Orang tua memegang peranan yang sangat penting dalam pembentukan kepribadian anak-anaknya, namun tidak kalah penting pendidikan di lingkungan sekolah juga merupakan salah satu tempat untuk membentuk iman anak. Berbicara mengenai peranan guru Pendidikan Agama Kristen dalam membentuk iman anak, maka ada kaitannya dengan pengaruh

\footnotetext{
${ }^{1}$ Rannu Sanderan, "Exemplary Menemukenali Kunci Pendidikan Iman Bagi Anak dalam Keluarga dan Pembelajaran Agama di Sekolah" (2021), https://osf.io/bmtrk/.
} 
perkembangan Ilmu Pengetahuan dan Teknologi (IPTEK) yang sangat pesat yang membuat karakter manusia menjadi sampingan dan tidak menjadi perhatian atau fokus utama.

Perkembangan ilmu pengetahuan dan teknologi atau perubahan zaman, tidak menjadi alasan bagi para pendidik untuk tidak mengajarkan Pendidikan Agama Kristen dan melakukan perannya sebagai guru yang dipercayakan oleh Kristus dalam mendidik dan membentuk iman dan karakter anak.

\section{TUJUAN DAN MANFAAT}

Dalam pandangan, John M. Nainggolan mengatakan tanggung jawab yang dipikul oleh setiap guru-guru Pendidikan Agama Kristen yang telah disediakan melingkupi sebagai berikut:

1) Sejauh mana Pendidikan Agama Kristen di sekolah mampu memberikan dampak yang baik bagi pertumbuhan iman anak pada saat ini.

2) Sejauh mana tanggungjawab sekolah dalam melaksanakan Pendidikan Agama Kristen kepada anak secara bertanggung jawab dan berkualitas.

3) Sejauh mana peranan guru Pendidikan Agama Kristen di sekolah mewujudkan tujuan Pendidikan Agama Kristen di Gereja.

4) Sejauh mana tanggung jawab orang tua dalam mendukung pelaksanaan tugas Pendidikan Agama Kristen di sekolah

Tujuan dan manfaat Pendidikan Agama Kristen dalam membangun iman anak dapat dimulai dari Guru sebagai pendidik. Guru adalah model (teladan) yang paling penting bahkan ampuh memengaruhi para murid. Karakter dan kepribadian seorang guru lebih dominan berpengaruh pada kehidupan murid-muridnya dibandingkan materi ajarnya sendiri. Memang tidak ada ukuran yang rigid untuk mengukur besarnya pengaruh, namun satu hal yang kita ketahui bersama adalah kehidupan exemplari dari seorang guru bisa berdampak kuat bagi pembentukan perihidup muridmuridnya. $^{2}$

\footnotetext{
${ }^{2}$ Rannu Sanderan, "Disiplin Asketisme dan Harmoni Kontribusi Disiplin Diri Bagi Pengembangan Pendidikan Kristen". (2021), https://osf.io/frsnz/.
} 


\section{PEMBAHASAN}

\section{A. Gerakan Guru Dalam Pendidikan Karakter}

Dasar pemikiran gerakan pendidikan karakter atau perhatian utama Pendidikan Agama Kristen ialah bahwa perilaku-perilaku menyimpang yang setiap hari membombardir kita, misalnya kekerasan, ketamakan, korupsi, ketidaksopanan, penyalahgunaan obat terlarang, asusila seksual, dan etika kerja yang buruk, mempunyai inti yang sama yakni tiadanya karakter yang baik. Perilaku-perilaku yang terjadi dilingkungan anak saat ini harus menjadi perhatian utama sekolah sebagai lembaga pendidikan, yang seharusnya membentuk karakter siswa. Guru harus melakukan gerakan pendidikan karakter yang dimulai dari dirinya sendiri, yakni menjadi contoh bagi siswa yang kemudian didukung oleh keluarga, gereja dan masyarakat. Keluarga, sekolah dan gereja adanya kerjasama yang baik, komunikasi yang baik antara sekolah dengan orang tua siswa dan dengan gereja. Dari ketiga lembaga tersebut, yang paling utama adalah keluarga. Harapan untuk masa depan ialah agar dapat mengambil tindakan bersama untuk meningkatkan karakter anak dan karakter kita sebagai orang dewasa dan akhirnya karakter kebudayaan kita dimulai dari keluarga yang kemudian dilanjutkan dengan sekolah dan gereja. ${ }^{3}$

Pada umumnya, guru hanya berperan sebagai pembimbing yang hanya mengajar anak dengan materi ajar. Guru menjadi pemimpin yang menyuruh anak muridnya di kelas, Anak hanya belajar untuk mendapatkan peringkat demi nama baik orangtua. Kepentingan anak menjadi semakin terabaikan karena anak hanya belajar untuk menyenangkan orangtua dan guru dengan mendapatkan nilai baik, demi untuk memenuhi kebutuhannya. ${ }^{4}$

Menurut KBBI, asketisisme adalah paham yg mempraktikkan kesederhanaan, kejujuran, dan kerelaan berkorban. Asketisme adalah ajaran-ajaran yang mengendalikan latihan rohani dengan cara mengendalikan tubuh dan jiwa sehingga tercapai kebijakankebijakan rohani khususnya dalam membentuk iman anak. ${ }^{5}$

\footnotetext{
${ }^{3}$ Rannu Sanderan, “Disiplin Asketisme dan Harmoni Kontribusi Disiplin Diri Bagi Pengembangan Pendidikan Kristen". (2021), https://osf.io/frsnz/.

${ }^{4}$ Rannu Sanderan, "Exemplary Menemukenali Kunci Pendidikan Iman Bagi Anak dalam Keluarga dan Pembelajaran Agama di Sekolah" (2021), https://osf.io/bmtrk/.

5 Ibid.
} 


\section{B. Tanggung Jawab Guru Pendidikan Agama Kristen}

Ada empat hal yang tidak kalah penting dalam menjalankan tugas dan tanggung jawab seorang guru Pendidikan Agama Kristen yang harus dimilikinya, yaitu sebagai berikut:

1) Guru Memberikan Dirinya Kepada Murid

Guru Pendidikan Agama Kristen merupakan faktor penting dalam mensukseskan kegiatan belajar mengajar. John M. Nainggolan tanggung jawab guru PAK adalah "guru memberi tenaga, waktu tanpa pamrih kepada murid-murid-Nya setia hari. Ini merupakan hal yang biasa yang dikerjakan oleh guru senantiasa dalam hidupnya". "Gembalakanlah kawanan domba Allah yang ada padamu, jangan dengan paksa, tetapi dengan sukarela sesuai dengan kehendak Allah, dan jangan karena mau mencari keuntungan, tetapi dengan pengabdian diri (1 Petrus 5:2)”.

2) Guru Menjadi Teladan Kepada Murid

Paulus sebagai seorang pengajar mengatakan kepada Timotius anak rohaninya bahwa "Jangan seorangpun menganggap engkau rendah karena engkau muda.Jadilah teladan bagi orang-orang percaya, dalam perkataanmu, dalam tingkah lakumu, dalam kasihmu, dalam kesetiaanmu dan dalam kesucianmu (1 Timotius 4:12)".

3) Guru Membawa Murid Pada Perjumpaan Dengan Kristus

Untuk bisa menemukan pribadi seseorang kepada Kristus, maka seseorang harus mengenal dan mengerti terlebih dahulu hal-hal berikut:

- Kristus dan keselamatan (Yesus Sebagai Juruselamat, Roma 3:23, Yohanes 3:16).

- Pertobatan dan iman (lahir baru).

- Kristus sebabai pusat kehidupan.

- Memelihara persekutuan dengan Allah".

4) Guru Membawa Murid Kepada Perubahan Hidup

Filosofis Pendidikan Agama Kristen menyadarkan kepada kita, perlunya pengajaran yang menekankan visi dan misi, seperti Kristus datang ke dunia yang memiliki visi dan misi yang jelas yaitu mencari yang hilang, mencari orang berdosa untuk diselamatkan. ${ }^{6}$

\footnotetext{
${ }^{6}$ Rannu Sanderan, “Disiplin Asketisme dan Harmoni Kontribusi Disiplin Diri Bagi Pengembangan Pendidikan Kristen". (2021), https://osf.io/frsnz/.
} 


\section{KESIMPULAN}

Guru Pendidikan Agama Kristen memiliki tugas yang sangat kompleks dan terpadu. Sebagai wujud nyata peranan guru Pendidikan Agama Kristen tersebut harus melaksanakan tugasnya dengan baik dan bertanggungjawab dalam mencapai tujuan pembelajaran yang sempurna. Salah satu tujuan Pendidikan Agama Kristen adalah siswa memiliki karakter yang baik seperti Tuhan Yesus Kristus.Sebab peran Guru Pendidikan Agama Kristen sangat berpengaruh terhadap pembentuk karakter siswa. Bahkan Alkitab memberikan keterangan bahwa Yesus memberikan wewenang kepada para rasul, para nabi, para pengajar, para gembala dan para penginjil untuk mengajar dan membentuk karakter jemaat (siswa) menjadi dewasa dan sempurna (Efesus 4:11-16). ${ }^{7}$

Karakter dan kepribadian yang dibentuk melalui katalisasi minat dan antusiasme merupakan modal yang besar untuk memeroleh pengaruh yang dapat membentuk karakter/iman anak. Dengan minat seseorang akan memperhatikan sesuatu objek belajar dengan mencurahkan sepenuh-penuhnya kesadaran, tenaga, waktu, peluang dan fasilitas yang dimilikinya demi mendalami objek belajarnya. ${ }^{8}$

\section{SARAN}

Seorang guru Pendidikan Agama Kristen perlu memperhatikan beberapa hal, yaitu:

a. Menjaga kekudusan hidupnya sebagai mitra Allah dalam membina, membimbing para muridnya menjadi murid yang berkarakter seperti Dia.

b. Menyadari bahwa dirinya adalah hamba Tuhan, tugas mengajar merupakan panggilan Allah yang harus dikerjakan dengan sungguh-sungguh. Guru Pendidikan Agama Kristen harus mempersiapkan dirinya sebaik mungkin sebelum mengajar.

c. Guru Pendidikan Agama Kristen harus menjadi teladan bagi siswa serta bersahabat dengan siswa sebagai bagian dari pembentukan karakter siswa.

\footnotetext{
${ }^{7}$ Rannu Sanderan, "Exemplary Menemukenali Kunci Pendidikan Iman Bagi Anak dalam Keluarga dan Pembelajaran Agama di Sekolah" (2021), https://osf.io/bmtrk/.

8 Ibid
} 


\section{DAFTAR PUSTAKA}

Rannu Sanderan, "Disiplin Asketisme dan Harmoni Kontribusi Disiplin Diri Bagi Pengembangan Pendidikan Kristen". (2021), https://osf.io/frsnz/.

Rannu Sanderan, "Exemplary Menemukenali Kunci Pendidikan Iman Bagi Anak dalam Keluarga dan Pembelajaran Agama di Sekolah" (2021), https://osf.io/bmtrk/. 